\section{Tissue Distribution of Perfluorinated Chemicals in Harbor Seals (Phoca vitulina) from the Dutch Wadden Sea}

KRISTIN INNEKE VAN DE VIJVER, ${ }^{*},+$ PHILIPPE HOFF, ${ }^{\dagger}$ KRISHNA DAS, ～$^{\ddagger}$

SOPHIE BRASSEUR, $\$$

WALTER VAN DONGEN, " EDDY ESMANS," PETER REIJNDERS, $₫$ RONNY BLUST, ${ }^{\dagger}$ AND WIM DE COEN ${ }^{\dagger}$

Department of Biology, University of Antwerp, Groenenborgerlaan 171, 2020 Antwerpen, Belgium, MARE Center, Laboratory for Oceanology, Liège University B6, B-4000, Liège, Belgium, Alterra - Marine and Coastal Zone Research, Post Office Box 167, 1790 AD Den Burg, The Netherlands, and Department of Chemistry, Nucleoside Research and Mass Spectrometry Unit, University of Antwerp, Groenenborgerlaan 171, 2020 Antwerpen, Belgium

Perfluorinated acids (PFAs) are today widely distributed in the environment, even in remote arctic areas. Recently, perfluorooctane sulfonate (PFOS) has been identified in marine mammals all over the world, but information on the compound-specific tissue distribution remains scarce. Furthermore, although longer perfluorinated carboxylic acids (PFCAs) are used in industry and were shown to cause severe toxic effects, still little is known on potential sources or their widespread distribution. In this study, we report for the first time on levels of longer chain PFCAs, together with some short chain PFAs, perfluorobutane sulfonate (PFBS) and perfluorobutanoate (PFBA), in liver, kidney, blubber, muscle, and spleen tissues of harbor seals (Phoca vitulina) from the Dutch Wadden Sea. PFOS was the predominant compound in all seal samples measured (ranging from 89 to $2724 \mathrm{ng} / \mathrm{g}$ wet weight); however, large variations between tissues were monitored. Although these are preliminary results, it is, to our knowledge, the first time that PFBS could be found at detectable concentrations $(2.3 \pm 0.7 \mathrm{ng} / \mathrm{g} \mathrm{w} \mathrm{wt})$ in environmental samples. PFBS was only detected in spleen tissue. PFCA levels were much lower than PFOS concentrations. The dominant PFCA in all tissues was PFNA (perfluorononanoic acid), and concentrations generally decreased in tissues for all other PFCA homologues with increasing chain length. No clear relationship between PFOS levels in liver and kidney was observed. Furthermore, hepatic PFDA (perfluorodecanoic acid) levels increased with increasing body length, but in kidney tissue, PFDA levels showed an inverse relationship with increasing body length. These data suggest large differences in tissue distribution and

\footnotetext{
* Corresponding author phone: +32 326533 50; fax: +32 3265 34 97; e-mail: inneke.vandevijver@ua.ac.be.

${ }^{\dagger}$ Department of Biology, University of Antwerp.

‡ Liège University.

${ }^{\S}$ Alterra.

" Department of Chemistry, University of Antwerp.
}

accumulation patterns of perfluorinated compounds in marine organisms.

\section{Introduction}

In past years, a growing concern has been expressed about perfluorinated acids (PFAs). These compounds have been produced for over 50 years, and due to their unique physicochemical properties, they have a broad application spectrum in industry and commerce as surfactants, adhesives, fire retardants, agrochemicals, and food packaging. Only recently, studies have documented the global distribution of PFAs, with perfluorooctane sulfonate (PFOS) as the most important representative, in animals of various trophic levels in the entire food chain (1). The presence of PFOS has also been established in commercially available nonindustrially exposed human blood (2). It has been shown that even surface and drinking water is already heavily contaminated with PFOS $(3,4)$. The spatial distribution becomes clearer; however, concentrations of PFAs are mainly described for environmental samples, in the United States (1), Canada (5), and the Pacific region (6). The degree of PFAs pollution in marine wildlife tissues in Western Europe is still scarcely documented $(7,8)$.

Furthermore, relatively little is known on the toxicity of these compounds to animals and humans. Most of the toxicity data gathered so far deal with mammals exposed to PFOS and PFOA, and serious chronic toxic effects have been reported for rats and apes. Several perfluorinated compounds have potent hepatic peroxisome proliferating capacities, a phenomenon that has been intimately correlated with hepatocarcinogenesis $(9,10)$. Further, among the effects known is induction of microsomal liver carboxylesterase RL4 in rats (11), and membrane-related effects were demonstrated in in vitro studies such as inhibition of gap junction intercellular communication $(12,13)$ and increase of membrane fluidity (14). Postnatal deaths and developmental problems were reported in rats in addition to weight loses, convulsions, and changes in liver enzymes in PFOS exposed monkeys (15).

To understand more about the mechanisms and pathways leading to the presence of PFAs in marine wildlife of Western Europe, we examined for the presence of perfluorochemicals in liver, kidney, blubber, muscle (skeletal and tracheobranchial muscle tissue), and spleen tissue of harbor seals (Phoca vitulina) stranded along the coastline of the Wadden Sea, situated in the northern part of The Netherlands. Furthermore, as the knowledge on the prevalence of longer chain perfluorinated fatty acids in the European marine environment is scarce, several long and short chain perfluorinated organochemicals were detected.

The harbor seal population in the Wadden Sea has declined from almost 40000 animals around 1900 to less than 10000 after the virus epidemic in 2002. Within this period, losses of harbor seals were mainly due to extensive hunting pressure and to two virus epidemics, one in 1988 and one in $2002(16,17)$, although environmental pollutants pose a constant threat to marine mammals as they are at the top of the aquatic food chain.

Within the North Sea, the Wadden Sea represents an interesting research site. The shallow and semi-enclosed part of the Dutch Wadden Sea is a nursery and a feeding zone of prime importance for the harbor seal population in the North Sea (18). Furthermore, at high tide, inflows of water from the North Sea into the Wadden Sea bring in a considerable 
amount of toxic compounds. In addition, several rivers, like the Rhine, Elbe, Weser, and Ems Rivers, with much industry and agriculture in their river basin, have mouths in the Wadden Sea. Chemicals present in these waters are the main factor causing the relatively high degree of pollution of the Wadden Sea. Furthermore, the Wadden Sea lies at the edge of Northwest Europe, and an important pollution source is formed by atmospheric deposition from highly industrialized countries in Northwest and Central Europe.

\section{Materials and Methods}

Sampling Procedure. In 2002, more than 10000 dead seals (about $40 \%$ of the estimated seal stock) were registered in the entire Wadden Sea as a consequence of the phocine distemper virus (PDV) infection $(19,20)$. Harbor seals found dead along the Dutch coasts (Texel and Northern Netherlands) during the 2002 epizooty were collected and necropsied according to standard procedure. Liver, kidney, blubber, skeletal muscle, and spleen tissues were sampled and stored at $-20^{\circ} \mathrm{C}$ until further analysis. From one harbor seal, it was possible to collect tracheo-bronchial muscle tissue, taken close to the heart and kidneys.

PFAs Analysis. Tissue extracts were analyzed using high performance liquid chromatography combined with electrospray tandem mass spectrometry (LC-MS/MS) as described by Hansen et al. (21) with some minor modifications described by Hoff et al. (22).

Shortly, $1 \mathrm{~g}$ of soft tissue was homogenized on ice with an MSE $150 \mathrm{~W}$ ultrasonic disintegrator (MSE Scientific instruments, Sussex, UK) with $3 \mathrm{~mL}$ of Milli-Q water (Millipore, Belgium). Afterward, $500 \mu \mathrm{L}$ of homogenate, 10 $\mu \mathrm{L}$ of internal standard, $1 H, 1 H, 2 H, 2 H$-perfluorooctane sulfonate (Sigma-Aldrich Chemical Co., Milwaukee, WI), $1 \mathrm{~mL}$ of $0.5 \mathrm{M}$ tetrabutylammonium hydrogen sulfate solution (TBAS; adjusted to $\mathrm{pH} 10$ ), and $2 \mathrm{~mL}$ of $0.25 \mathrm{M}$ sodium carbonate buffer were thoroughly mixed. Five milliliters of methyl-tert-butyl ether (MBTE) was added, and the mixture was shaken for $2 \mathrm{~h}$ at $20^{\circ} \mathrm{C}(250 \mathrm{rpm})$. The organic and aqueous layers were separated by centrifugation, and 5.45 $\mathrm{mL}$ was removed from the aqueous layer. After the solvent was evaporated under a stream of $\mathrm{N}_{2}$, the extract was resuspended in $0.5 \mathrm{~mL}$ of methanol and filtered through a $0.2 \mu \mathrm{m}$ nylon mesh filter.

Perfluorooctanoic acid (PFOA; $\left.\mathrm{CF}_{3}\left(\mathrm{CF}_{2}\right)_{6} \mathrm{CO}_{2} \mathrm{H}\right)$, perfluorononanoic acid (PFNA; $\mathrm{CF}_{3}\left(\mathrm{CF}_{2}\right)_{7} \mathrm{CO}_{2} \mathrm{H}$ ), perfluorooctane sulfonate (PFOS; $\left.\mathrm{CF}_{3}\left(\mathrm{CF}_{2}\right)_{7} \mathrm{SO}_{3} \mathrm{H}\right)$, perfluorodecanoic acid (PFDA; $\mathrm{CF}_{3}\left(\mathrm{CF}_{2}\right)_{8} \mathrm{CO}_{2} \mathrm{H}$ ), perfluoroundecanoic acid (PFUnA; $\mathrm{CF}_{3}\left(\mathrm{CF}_{2}\right)_{9} \mathrm{CO}_{2} \mathrm{H}$ ), and perfluorododecanoic acid (PFDoA; $\left.\mathrm{CF}_{3}\left(\mathrm{CF}_{2}\right)_{10} \mathrm{CO}_{2} \mathrm{H}\right)$ were measured in all of the samples following the same procedure. Briefly, HPLC was done on a CapLC system (Waters, Millford, MA) connected to a Quattro II triple quadrupole mass spectrometer (Micromass, Manchester, UK). Aliquots of $5 \mu \mathrm{L}$ of extract were loaded on an Optiguard C18 precolumn $(10 \mathrm{~mm} \times 1 \mathrm{~mm}$ i.d., Alltech, Sercolab, Belgium), followed by a Betasil C18 column (50 $\mathrm{mm} \times 1 \mathrm{~mm}$ i.d., Keystone Scientific, Bellefonte, PA) at a flow rate of $40 \mu \mathrm{L} / \mathrm{min}$. The mobile phase was $2 \mathrm{mM} \mathrm{NH}_{4}{ }^{-}$ $\mathrm{OAc} / \mathrm{methanol}$, starting at $10 \%$ methanol and increasing to $90 \%$ in $8 \mathrm{~min}$. After $10 \mathrm{~min}$, initial conditions were resumed. However, for the measurement of PFBS $\left(\mathrm{CF}_{3}\left(\mathrm{CF}_{2}\right)_{3} \mathrm{SO}_{3} \mathrm{H}\right)$ and PFBA $\left(\mathrm{CF}_{3}\left(\mathrm{CF}_{2}\right)_{2} \mathrm{CO}_{2} \mathrm{H}\right), 0.1 \%$ of formic acid was used instead of $2 \mathrm{mM} \mathrm{NH}_{4} \mathrm{OAc}$. All components were measured under negative electrospray ionization using the following transitions: $213 \rightarrow 169$ (PFBA), 299 $\rightarrow 99$ (PFBS), 413 $\rightarrow 369$ (PFOA), $463 \rightarrow 419$ (PFNA), 499 $\rightarrow 99$ (PFOS), 513 $\rightarrow 469$ (PFDA), 563 $\rightarrow 519$ $(\mathrm{PFUnA})$, and $613 \rightarrow 569$ (PFDoA). The internal standard, $1 H, 1 H, 2 H, 2 H$-perfluorooctane sulfonate (Sigma-Aldrich Chemical Co., Milwaukee, WI), was measured under the same conditions $(427 \rightarrow 81)$. No other standards were included. The dwell time was $0.1 \mathrm{~s}$. The ES-capillary voltage was set at -3.5
$\mathrm{kV}$, and the cone voltage was $24 \mathrm{~V}$ (35 V for measurements of PFBA and PFBS). The source temperature was $80^{\circ} \mathrm{C}$. The pressure in the collision cell was $3.310^{-5} \mathrm{mmHg}$ (Ar). These settings were the same for all measurements. The limit of quantitation (LOQ) of PFOS was $1.49 \mathrm{ng} / \mathrm{g}$ wet weight (wet wt), whereas for the other measured compounds it varied from 1.39 to $62 \mathrm{ng} / \mathrm{g}$ wet wt. Data quality assurance and quality control protocols include matrix spike, laboratory blanks, and continuing calibration verification. Recoveries of PFOS (Sigma-Aldrich Chemical Co., Milwaukee, WI) spiked into harbor porpoise liver tissue and passed through the analytical procedure varied from $69 \%$ to $108 \%$. The PFOS standard was $98 \%$ pure. Concentrations were evaluated versus an unextracted standard curve and were not corrected for the recoveries or for the purity of the PFOS standard. The repeatability and reproducibility were $83 \%$ and $86 \%$, respectively.

Stable Isotope Measurements. The data on the stable isotope measurements in harbor seals from the Wadden Sea are presented elsewhere (23) and were integrated in this study. Briefly, carbon dioxide and nitrogen gas were analyzed on a V.G. Optima (Micromass) isotope ratio-mass spectrometer (IR-MS) coupled to an $\mathrm{N}-\mathrm{C}-\mathrm{S}$ elemental analyzer (Carlo Erba).

Data Treatment. The normality of the data was analyzed by means of a Kolmogorov-Smirnov test. A log-transformation was done to ensure normality of the distribution of PFOS concentrations in all tissues. A 2-way analysis of variance (ANOVA) was performed to look for differences in toxicant levels between the tissues and sexes. The Scheffé test was used as post-hoc criterion.

Possible sex- and age-related PFOS tissue level differences were analyzed in detail, by means of a standard canonical discriminant analysis (CDA), including all PFOS concentrations measured in all tissues, $\delta^{15} \mathrm{~N}$, weight, and length, as dependent variables. The mean values of the first two canonical variables (CV) were used to plot the different sex/ age groups on a two-dimensional graph, superimposing the eigenvector values of the independent variables.

Finally, associations between PFACs levels in the liver and kidney, with weight, length, $\delta^{15} \mathrm{~N}$, body weight, and kidney weight, were investigated by means of two canonical correlation analyses (CCA). All statistical analysis were performed with the Statistica 6.0 package (Statsoft Inc., Tulsa, Oklahoma, US) and interpreted at $1 \%$ significance level.

\section{Results}

Perfluorinated Sulfonate Levels in the Tissues. Levels of perfluorinated sulfonates in kidney, liver, muscle, blubber, and spleen are shown in Table 1.

In all individuals and in all tissues, PFOS was the predominant compound. Due to the small sample size of spleen and tracheo-bronchial muscle tissue, no relevant comparison with these tissues could be performed. Significant differences between the other tissue concentrations of PFOS are shown in Figure 1.

A tendency of increasing PFOS concentration was seen in the order kidney $>$ liver $>$ blubber $>$ skeletal muscle, although it is worth mentioning that the highest PFOS concentration (2725 ng/g w wt) was found in tracheobronchial muscle tissue. Mean concentrations of PFOS in spleen were rather high ( $307 \pm 120 \mathrm{ng} / \mathrm{g} \mathrm{w} \mathrm{wt})$ as compared to the other tissues, but only four harbor seals could be analyzed. Apparently, there was no influence of the gender on the PFOS concentrations in the different tissues (ANOVA $p>0.05)$. There was a trend that female seals had higher PFOS levels than male seals in their livers and kidneys; however, in blubber and muscle tissue, the opposite relation could be found (Figure 2). 
TABLE 1. Concentrations of Perfluorinated Sulfonates and Carboxylates in Kidney, Liver, Blubber, Muscle, and Spleen Tissue (ng $\mathrm{g}^{-1}$ Wet Weight) of Harbor Seals from the Dutch Wadden Sea

\begin{tabular}{|c|c|c|c|c|c|c|c|c|c|}
\hline & & PFBA & PFOA & PFNA & PFDA & PFUA & PFDoA & PFBS & PFOS \\
\hline $\begin{array}{l}\text { kidney } \\
n=18\end{array}$ & $\begin{array}{l}\text { minimum } \\
\text { maximum } \\
\text { median } \\
\text { mean } \pm S D\end{array}$ & $<$ LOD & $\begin{array}{l}<\text { LOD } \\
11.59\end{array}$ & $\begin{array}{l}<\text { LOD } \\
60.41\end{array}$ & $\begin{array}{l}<\text { LOD } \\
46.19\end{array}$ & $\begin{array}{l}<\text { LOD } \\
25.46\end{array}$ & $\begin{array}{l}<\text { LOD } \\
3.42\end{array}$ & $<$ LOD & $\begin{array}{r}46.83 \\
1035.77 \\
319.30 \\
378.46 \pm 272.92\end{array}$ \\
\hline $\begin{array}{l}\text { liver } \\
n=24\end{array}$ & $\begin{array}{l}\text { minimum } \\
\text { maximum } \\
\text { median } \\
\text { mean } \pm \mathrm{SD}\end{array}$ & $<$ LOD & $<$ LOD & $\begin{array}{l}<\text { LOD } \\
14.00\end{array}$ & $\begin{array}{l}1.76 \\
14.11\end{array}$ & $\begin{array}{l}<\text { LOD } \\
7.88\end{array}$ & $<$ LOD & $<$ LOD & $\begin{array}{l}45.84 \\
488.26 \\
160.53 \\
175.29 \pm 104.99\end{array}$ \\
\hline $\begin{array}{l}\text { blubber } \\
n=17\end{array}$ & $\begin{array}{l}\text { minimum } \\
\text { maximum } \\
\text { median } \\
\text { mean } \pm \mathrm{SD}\end{array}$ & $<$ LOD & $<$ LOD & $<$ LOD & $<$ LOD & $<$ LOD & $<$ LOD & $<$ LOD & $\begin{array}{c}18.90 \\
296.91 \\
44.83 \\
100.21 \pm 83.47\end{array}$ \\
\hline $\begin{array}{l}\text { muscle } \\
n=18\end{array}$ & $\begin{array}{l}\text { minimum } \\
\text { maximum } \\
\text { median } \\
\text { mean } \pm S D\end{array}$ & $<$ LOD & $<$ LOD & $\begin{array}{l}<\text { LOD } \\
11.99\end{array}$ & $\begin{array}{l}<\text { LOD } \\
15.40\end{array}$ & $\begin{array}{l}<\text { LOD } \\
6.35\end{array}$ & $<$ LOD & $<$ LOD & $\begin{array}{r}8.85 \\
515.03 \\
24.54 \\
59.36 \pm 117.39\end{array}$ \\
\hline $\begin{array}{l}\text { tracheo-branchial muscle } \\
\qquad n=1\end{array}$ & & $<$ LOD & $<$ LOD & 69.82 & 59.10 & 30.23 & $<$ LOD & $<$ LOD & 2724.58 \\
\hline $\begin{array}{l}\text { spleen } \\
n=4\end{array}$ & $\begin{array}{l}\text { minimum } \\
\text { maximum } \\
\text { median } \\
\text { mean } \pm \mathrm{SD}\end{array}$ & $<$ LOD & $<$ LOD & $\begin{array}{l}<\text { LOD } \\
22.77\end{array}$ & $\begin{array}{l}6.07 \\
21.86 \\
11.65 \\
12.81 \pm 6.66\end{array}$ & $\begin{array}{l}3.18 \\
11.05 \\
8.30 \\
7.71 \pm 3.29\end{array}$ & $<$ LOD & $\begin{array}{l}1.74 \\
3.28 \\
2.17 \\
2.34 \pm 0.68\end{array}$ & $\begin{array}{l}151.77 \\
438.54 \\
319.58 \\
307.37 \pm 120.1\end{array}$ \\
\hline
\end{tabular}

${ }^{a}$ Concentrations did not differ significantly between male and female harbor seals; all individuals were therefore pooled.

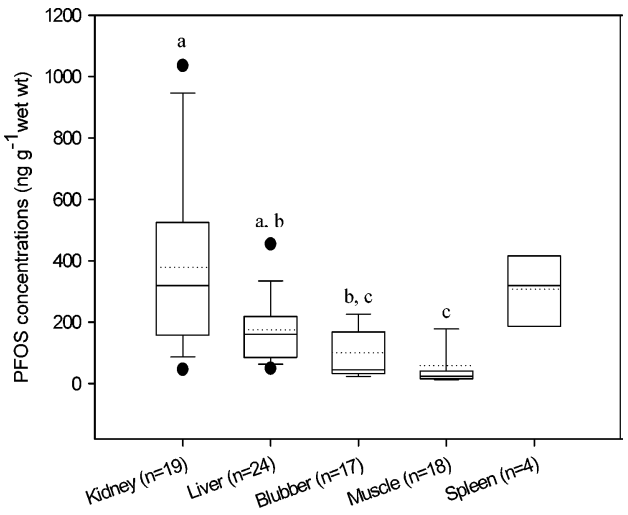

FIGURE 1. Concentrations of perflurooctane sulfonate $(\mathrm{ng} / \mathrm{g}$ wet weight) in different tissues of harbor seals (Phoca vitulina) from the Dutch Wadden Sea. The straight line is the median, and the dotted line represents the mean. The 25th and 75th percentiles define the boxes. The whiskers represent the 10th and 90th percentiles, while the dots represent the 5th and 95th percentiles. The letters " $a$ " and " $b$ " indicate the significant differences between the groups.

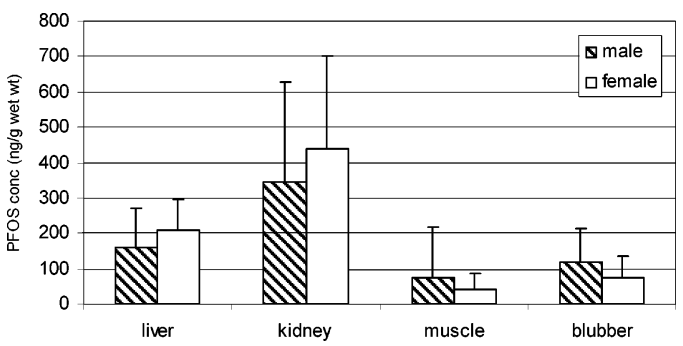

FIGURE 2. Difference in mean perfluorooctane sulfonate (PFOS) concentrations and standard deviations in different tissues of harbor seals (Phoca vitulina) between males and females. In none of the cases was the difference statistically significant $(p>$ 0.05).

In liver, blubber, and muscle, adult males had the highest mean levels of PFOS as compared to male juveniles, in contrast to kidney tissue, where the highest mean concentration was found in juveniles (Figure 3).

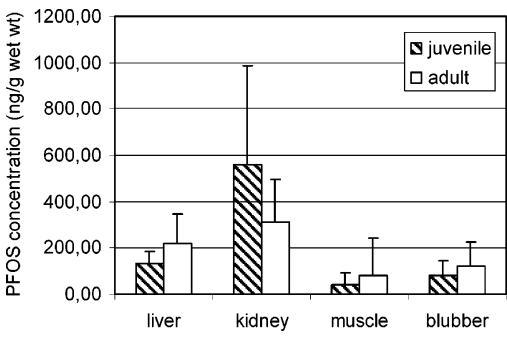

FIGURE 3. Difference in mean perfluorooctane sulfonate (PFOS) concentrations and standard deviations in different tissues of harbor seals (Phoca vitulina) between juveniles and adults. In none of the cases was the differenc statistically significant $(p>0.05)$.

Although levels were low, PFBS could only be detected in spleen samples (Table 1). Concentrations varied between 1.7 and $3.3 \mathrm{ng} / \mathrm{g} \mathrm{w}$ wt, with a mean concentration of $2.3 \pm$ $0.68 \mathrm{ng} / \mathrm{g}$ w wt.

To evaluate similarities in the PFOS concentrations of the different tissues, the $\delta^{15} \mathrm{~N}$ values, length, and weight of the harbor seals among the different gender and age classes, a canonical discriminant analysis (CDA) was performed (Figure 4). Discriminant analysis shows how several predefined groups of individuals may be separated, given measurements of several variables. It provides linear functions of the variables that best separate the cases into the predefined groups. As only one sample of an adult female seal was analyzed, adult females were not included in the analysis.

We could discriminate three harbor seal groups discriminated by their PFOS levels in the liver and their weight. The first canonical variable (CV1) of the CDA explained $80.94 \%$ of the total variation. The horizontal axis (CV1) mainly discriminated between juveniles (Group I) / subadults (Group II) and adults (Group III) irrespective from the sex. This CV axis indicated that an increase in hepatic PFOS levels was associated with older animals, which were, as shown by the opposed size/weight relationship, relatively more fat as compared to the juveniles and subadults. Juvenile male and female seals (Group 1) are situated close together in the diagram and could not be discriminated on the basis of the different PFOS levels. Furthermore, the canonical discriminant analysis revealed a strong correlation between PFOS 


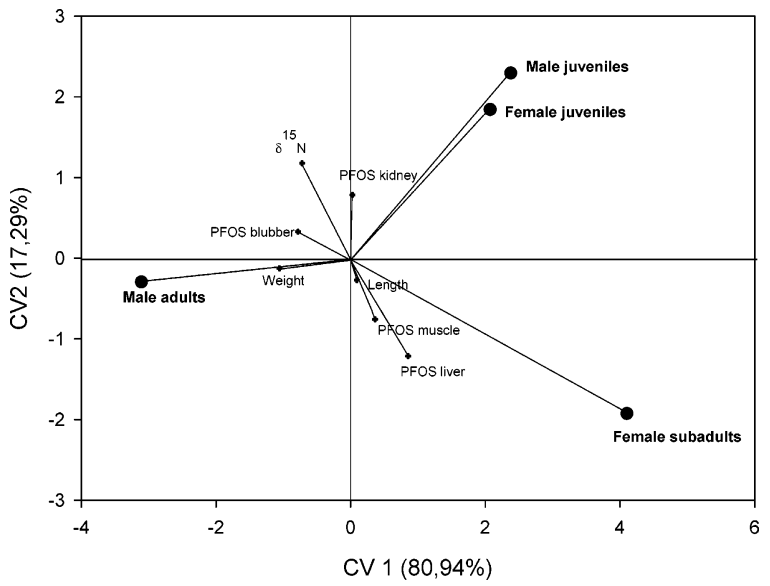

FIGURE 4. Graphical representation of the Canonical Discriminant Analysis, including all PFOS concentrations measured in all tissues, $\delta^{15} \mathrm{~N}$, weight, and length as dependent variables. The mean values of the first two canonical variables (CV) were used to plot the different sex/age groups on a two-dimensional graph, superimposing the eigenvector values of the independent variables.

concentrations in liver and muscle tissue. However, the large angle between the vector of the PFOS levels in the liver and the vector of the PFOS levels in the kidney and the blubber suggests that no apparent relationships could be established between PFOS levels in the liver, kidney, and blubber. According to the CDA, the highest trophic positions (i.e., high $\delta^{15} \mathrm{~N}$ values) were associated with adult seals, although no significant differences were detected via the unpaired $t$-test.

Perfluorinated Carboxylic Acid (PFCA) Levels in the Tissues. It was noteworthy that the concentrations of PFCAs were fairly low in all analyzed samples (Table 1) and there were no obvious differences between the different tissues. Only for PFUnA were significantly higher concentrations detected in kidney tissue than in liver tissue $(p=0.01)$. Of all long-chained perfluorinated fatty acids, PFNA was the major contaminant, and concentrations decreased with increasing chain length. PFOA was not observed in any of the samples, due to the high method detection limit of 62 ng/g wet wt. The highest PFCA concentrations were observed in one sample of tracheo-bronchial muscle tissue (ranging from $<1.84$ to $69.82 \mathrm{ng} / \mathrm{g}$ wet wt).

A comparison of any two PFCA homologue concentrations always produced a significant positive linear association ( $p$ $<0.001)$. Furthermore, animals with the highest PFOS concentrations almost always had also the highest PFCA concentrations in the different tissues.

A canonical correlation analysis was performed between PFNA, PFUnA, and PFDoA concentrations on one hand and weight, length, weight of the kidney, and $\delta^{15} \mathrm{~N}$ values on the other hand (Table 2). The analysis was done for both liver ( $p=0.01$ and $r=0.56)$ and kidney ( $p<0.0001$ and $r=0.63$ ) tissue. Both analyses revealed the previously detected (CDA, Figure 3) opposite orientated size/weight relationship.

In liver tissue, all PFCA concentrations increased significantly with increasing length (positive eigenvalue), whereby PFDA showed the largest effect (highest eigenvalue) and PFUnA was hardly influenced (lowest eigenvalue). However, in kidney tissue, PFDoA levels decreased with increasing body length (negative eigenvalue).

Adult male harbor seal livers have higher PFCA concentrations than do juvenile male seal livers $(p>0.05)$. However, in kidney tissue, mean concentrations of PFCAs are generally higher in juveniles than in adults $(p>0.05)$.
TABLE 2. Associations between PFACs Levels in the Liver and Kidney, with Weight, Length, $\delta^{15} \mathrm{~N}$, Body and Kidney Weight, Were Investigated by Means of Two Canonical Correlation Analyses (CCA) and Presented as Eigenvalues

liver $(p=0.01, r=0.56)$

eigenvalue

D15N

length

weight

0.005

weight kidney

1.67

PFOS

PFNA

PFDA

$-0.909$

$-0.073$

0.159

0.160

PFUA

0.711

0.065

kidney $(\boldsymbol{p}<\mathbf{0 . 0 0 0 1 ,} \boldsymbol{r}=\mathbf{0 . 6 3})$
D15N
length
weight
weight kidney
PFOS
PFNA
PFDA
PFUA

eigenvalue
0.006
1.5506
-1.08
0.37
0.66
0.95
-3.16
1.798

\section{Discussion}

Perfluorooctane Sulfonate: Geographical Comparison. The observed PFOS concentrations in liver of harbor seals from the Wadden Sea were higher as compared to those in harbor seals stranded along the coast of the Southern North Sea (7), but this observation can be linked to the fact that the juvenile seals from the Wadden Sea are larger and thus older than the juveniles from the Belgian coasts. These results are interesting, because harbor seals from the Southern North Sea and the Wadden Sea are believed to be from one population, and the observation that both groups reflect the same pollution levels supports this hypothesis. In addition to these data, a comparison with another sympatric species, the harbour porpoise (Phocoena phocoena), revealed also higher levels in both liver and kidney tissue from harbor seals. However, PFOS concentrations in seals from the Wadden Sea were similar to those in harbor porpoises originating from Denmark and the Baltic Sea (8). Both species share the same environment and some of their prey species, but differ in trophic position and metabolism of organic pollutants, which might explain the difference in toxic levels $(24,25)$. However, a more logical explanation for both observations might be the geographical position of the monitoring sites. The influence of the semi-enclosed character of waters such as the Wadden Sea and the Baltic Sea might contribute to the higher degree of pollution in these systems (8).

Hepatic PFOS concentrations in Dutch seals were lower as compared to those in other species, such as gray seal (Halichoerus grypus) and ringed seal (Phoca hispida) from the Bothnian Bay (26). Harbor seals originating from the west coast of the U.S. contained much lower concentrations $(1,27)$, just like Canadian ringed seals (5). Occurrence of higher concentrations in animals from coastal waters within Western Europe and the Baltic Sea can be explained by the closeness of highly industrialized regions and the presence of possible pollution sources. Although there is only sparse information concerning perfluorochemical production plants in Western and Eastern Europe, large end-user industries might have an influence on the total pollution burden of an animal, including the presence of perfluorinated sulfonates.

Tissue Distribution of PFOS. Because of the small sample size, PFOS concentrations, measured in the spleen and tracheo-bronchial muscle tissues, were omitted from the statistical tissue comparative PFOS analysis. Nonetheless, 
spleen and tracheo-bronchial muscle PFOS levels do have a descriptive value and as such are used in the context of the tissue PFOS/PFBS distribution discussion section that follows.

In the present study on harbor seals from the Dutch Wadden Sea, increasing PFOS concentrations were seen in the order kidney $>$ liver $>$ blubber $>$ skeletal muscle (Figure 1). Significant differences between the tissues were comparable to tissue distribution patterns found in rainbow trout after exposure to several perfluorinated acids (28). Unlike most persistent organic pollutants and due to their surfactantlike structure, perfluorinated chemicals accumulate to a higher extent in kidney and liver, as compared to blubber/ fat or skeletal muscle. The fact that the PFOS liver and kidney level vectors are oppositely orientated in the CDA (Figure 4) may suggest that PFOS follows different accumulation patterns (i.e., age dependent) in both organs. Nevertheless, PFOS levels can still reach high levels in both the liver as well as the kidney. Although it only concerns one sample, the high concentration found in tracheo-bronchial muscle tissue is worth mentioning and might be explainable by the origin of this tissue. In contrast to skeletal muscle, which is taken under the blubber layer and which does not stay in contact with a certain organ, tracheo-bronchial muscle is connected with heart and kidney tissue. Whether this relationship points to a specific interaction or exchange between the organs remains to be elucidated.

Concentrations of PFOS found in spleen were rather high, although not comparable to the other tissues due to the small sample size and also not comparable to other studies, due to the low recovery of the compounds from the spleen in these studies (28).

PFOS in Relation to Sex and Age. The trend visible in female harbor seals (Figure 2), having higher hepatic and kidney PFOS concentrations than males, is similar to that described in harbor seals from the southern North Sea (7). In the present study, there is also a trend showing that concentrations are increasing with age in liver, blubber, and muscle tissue (Figure 3). However, PFOS levels in kidney tissue seem to follow a different pattern with higher concentrations in adult animals. Earlier studies on marine mammals have not yet found an explanation for the differences in exposure levels between females and males, nor for differences between adults and juveniles. Moreover, results differ between studies and depend on which animal and which tissue has been taken, although most of the studies are done using liver tissue. Concentration of PFOS did not increase with age in ringed or gray seals from the Bothnian Bay (26). Although concentrations were higher in adult polar bears from Alaska waters than in juveniles, the trend was not significant (27), and, in addition with this trend, an agerelated increase of PFOS liver concentration was observed in mice from Blokkersdijk, Belgium (29). However, juvenile harbor porpoises from the southern North Sea contained higher hepatic PFOS concentrations than adults (7). It is worth considering that an increase with age might have an influence on the overall health status of an animal. As an individual ages, the likelihood that random mutations will contribute to initiating events goes up (30), and thus chronic exposure over long periods to tumor promoters, such as PFAs, greatly increases the cancer risk of these chemicals.

Perfluorobutane Sulfonate. In the present study, it is the first time that detectable concentrations of PFBS were found in wildlife (Table 1). After the voluntary manufacturing phaseout of PFOS by the main producer, this compound was announced as official successor for the PFOS-related products (31). According to them, PFBS-based surfactants, with only four perfluorinated carbon atoms, offer improved environmental properties. PFBS has not been shown to accumulate in biota, and, until present, no PFBS traces were confirmed in biota samples yet. Previous studies have measured PFBS in water, fish, and beef cattle; however, none of the concentrations were above the limit of detection (32-34). Although concentrations of PFBS were low in seals from the Dutch Wadden Sea, it is remarkable that PFBS was only measured in spleen and not in the other tissues. PFBS and PFOS have similar functional groups, and, therefore, one could expect both compounds in tissues with similar PFOS concentrations, such as spleen and kidney. It seems that the difference in carbon chain lengths between PFBS and PFOS, and the target organ itself, plays a key role in the accumulation behavior of the compounds.

It is unclear what, if any, would be the likely consequence of the presence of PFBS in spleen tissue. In higher animals, the spleen fulfills central functions in the immune system. Therefore, it is highly sensitive to damage by contaminants and thus routinely examined in connection with immunotoxicological evaluations. So far, we are aware of no studies in which the toxicity of PFBS has been described. Hu et al. (13) tested the influence of perfluorinated compounds on the gap junctional intercellular communication, but PFBS showed no significant effects. PFBS had also no effect on the alterations in cell membrane properties in the concentration range tested (14). Furthermore, PFBS did not produce any developmental or reproductive effects in rats (35). However, exposure to another perfluorinated compound, which also acts as a potent peroxisome proliferator, PFOA, caused splenic atrophy in mice (36). To what extent specific immunological effects can be caused by PFBS is something that needs further investigation.

Perfluorinated Carboxylic Acids. Most of the studies conducted in past years have focused on perfluorooctane sulfonate (PFOS) and to a lesser extent on perfluorooctanoic acid (PFOA). To our knowledge, only a few studies have looked at longer perfluoroalkyl carboxylates (PFCAs) in organisms from the marine environment $(5,7,8)$. The perfluorocarboxylates could also be detected in harbor seals from the Wadden Sea, although at much lower concentrations than PFOS. PFNA was the dominant PFCA in all samples analyzed and concentrations decreased in general with increasing chain length, although some of the animals had higher hepathic PFDoA concentrations as compared to PFNA concentrations.

Similar results were reported by Van de Vijver et al. (8) in harbor porpoises from Northern Europe, except for porpoises from the Baltic sea, where PFNA concentrations were lower than those of PFDoA and PFUnA. In the study of Martin et al. (5), ringed seals had higher concentrations of PFUnA as compared to PFDoA, but the same results as in the present study were reported in polar bears and fox. In addition, concentrations of PFNA, PFDoA, and PFUnA measured in seals from the Dutch Wadden Sea were, respectively, 1.6, 3.7, and 1.3 times higher than levels measured in ringed seals from the Canadian artic, but still 10-20 times lower than in polar bears.

A much shorter component, PFBA with a chain length of 4 carbon molecules, could not be measured in any of the animals. The reason for this observation is unknown, but the low contamination level might be a result of the minor use of this compound in industrial applications so far.

The positive linear association between two PFCAs suggests that exposure to both PFCA compounds occurs together. These perfluorocarboxylates could have the same origin as PFOS because animals with the highest PFOS concentrations almost always had also the highest PFCA concentrations.

Although no clear explanation can be given for the strong correlation found between body length and hepatic PFDoA levels, it might be possible that there is an age specific influence. Hepatic PFCA concentrations are higher in adult males than in juveniles, and adult seals differ significantly 
from juveniles in body length ( $p<0.0001$ ). A study on Dall's porpoises (37) reported a similar result, where organochlorine concentrations were positively correlated with body length.

To conclude, levels of perfluorinated compounds remain, with some exceptions, rather low in harbor seals from the Wadden Sea as compared to concentrations found in tissues from wildlife from inland waters and terrestrial animals, but there might still be an impact on the general health status of the animals. A remarkable observation is the presence of PFBS at detectable concentrations in spleen tissue. It is the first time that PFBS could be detected in environmental samples. The difference seen between PFAs accumulation patterns in liver and kidney and the fact that there is no clear age or gender specific effect, except for PFOS where there is an age-related increment trend, suggests once more that these compounds are not acting in a straightforward way as, for example, do organochlorine compounds such as PCBs. Although this study gives a first indication about the difference in tissue distribution, further research on a larger sampling and other species and tissues will provide a better understanding of accumulation routes of the various perfluorinated chemicals.

\section{Acknowledgments}

We are grateful to Thierry Jauniaux (ULg, Belgium) and Ursula Siebert (FTZ, Germany) for performing the necropsies. We also wish to thank Hans De Wolf for useful comments on the data treatment. K.IV.d.V. has received a grant from the FWOFlanders, Brussels, Belgium. K.D. is a postdoctoral researcher at the National Fund for Scientific Research (FNRS, Belgium). This work is financially supported by the European Union, Project PERFORCE (NEST-508967). This paper is MARE publication no. 069 .

\section{Literature Cited}

(1) Giesy, J. P.; Kannan, K. Global distribution of perfluorooctane sulfonate in wildlife. Environ. Sci. Technol. 2001, 35, 13391342.

(2) Kannan, K.; Corsolini, S.; Falandysz, J.; Fillmann, G.; Kumar, K. S.; Loganathan, B. G.; Mohd, M. A.; Olivero, J.; Van Wouwe, N.; Yang, J. H.; Aldous, K. M. Perfluorooctanesulfonate and related fluorochemicals in human blood from several countries. Environ. Sci. Technol. 2004, 38, 4489-4495.

(3) Saito, N.; Sasaki, K.; Nakatome, K.; Harada, K.; Yoshinaga, T.; Koizumi, A. Perfluorooctane sulfonate concentrations in surface water in Japan. Arch. Environ. Contam. Toxicol. 2003, 45, 149158.

(4) Harada, K.; Saito, N.; Sasaki, K.; Inoue, K.; Koizumi, A. Perfluorooctane sulfonate contamination of drinking water in the Tama River, Japan: estimated effects on resident serum levels. Bull. Environ. Contam. Toxicol. 2003, 71, 31-36.

(5) Martin, J. W.; Smithwick, M. M.; Braune, B. M.; Hoekstra, P. F.; Muir, D. C.; Mabury, S. A. Identification of long-chain perfluorinated acids in biota from the Canadian Arctic. Environ. Sci. Technol. 2004, 38, 373-380.

(6) Saito, N.; Harada, K.; Inoue, K.; Sasaki, K.; Yoshinaga, T.; Koizumi, A. Perfluorooctanoate and perfluorooctane sulfonate concentrations in surface water in Japan. J. Occup. Health 2004, 46, $49-59$.

(7) Van de Vijver, K. I.; Hoff, P.; Das, K.; Van Dongen, W.; Esmans, E.; Jauniaux, T.; Bouquegneau, J. M.; Blust, R.; De Coen, W. Perfluorinated Chemicals Infiltrate Ocean Waters: Link between Exposure Levels and Stable Isotope Ratios in Marine Mammals. Environ. Sci. Technol. 2003, 37, 5545-5550.

(8) Van de Vijver, K. I.; Hoff, P.; Das, K.; Van Dongen, W.; Esmans, E.; Siebert, U.; Bouquegneau, J. M.; Blust, R.; De Coen, W. Baseline study of perfluorochemicals in harbour porpoises (Phocoena phocoena) from Northern Europe. Mar. Pollut. Bull. 2004, 48, 986-1008.

(9) Sohlenius, A. K.; Eriksson, A. M.; Högström, C.; Kimland, M.; DePierre, J. W. Perfluorooctane Sulfonic Acid is a Potent Inducer of Peroxisomal Fatty Acid $\beta$-Oxidation and Other Activities Known to be Affected by Peroxisome Proliferators in Mouse Liver. J. Pharmacol. Toxicol. 1993, 72, 90-93.

(10) Ikeda, T.; Fukuda, K.; Mori, I.; Enomoto, M.; Komai, T.; Suga, T. Induction of Cytochrome P-450 and Peroxisome Proliferation in Rat Liver by Perfluorinated Octane Sulfonic Acid (PFOS). In Peroxisomes in biology and medicine; Fahimi, H. D., Sies, H., Eds.; Springer-Verlag: New York, 1987; pp 304-308.

(11) Derbel, M.; Hosokawa, M.; Satoh, T. Difference in the induction of carboxylesterase RL4 in rat liver microsomes by various perfluorinated fatty acids, metabolically inert derivates of fatty acids. Biol. Pharm. Bull. 1996, 19, 765-767.

(12) Upham, B. L.; Deocampo, N. D.; Wurl, B.; Trosko, J. E. Inhibition of Gap Junctional Intercellular Communication by Perfluorinated Fatty Acids is Dependent on the Chain Length of the Fluorinated Tail. Int. J. Cancer 1998, 78, 491-495.

(13) Hu, W.; Jones, P. D.; Upham, B. L.; Trosko, J. E.; Lau, C.; Giesy, J. P. Inhibition of Gap Junctional Intercellular Communication by Perfluorinated Compounds in Rat Liver and Dolphin Kidney Epithelial Cell Lines in Vitro and Sprague-Dawley Rats in Vivo. Mol. Genet. Toxicol. 2002, 68, 429-436.

(14) Hu, W.; Jones, P. D.; De Coen, W.; King, L.; Fraker, P.; Newsted, J.; Giesy, J. P. Alterations in cell membrane properties caused by perfluorinated compounds. Comp. Biochem. Physiol., C2003, 135, 77-88.

(15) Renner, R. Growing concern over Perfluorinated Chemicals. Environ. Sci. Technol. 2001, 35, 154A-160A.

(16) Reijnders, P. J. H.; Ries, E. H.; Tougaard, S.; Norgaard, N.; Heidemann, G.; Schwarz, J.; Vareschi, E.; Traut, I. M. Population development of harbour seals Phoca vitulina in the Wadden Sea after the 1988 virus epizootic. J. Sea Res. 1997, 38, 161-168.

(17) Ries, E. H.; Traut, I. M.; Brinkman, A. G.; Reijnders, P. J. H. Net dispersal of harbour seals within the Wadden Sea before and after the 1988 epizootic. J. Sea Res. 1999, 41, 233-244.

(18) De Jong, F.; Bakker, J. F.; van Berkel, C. J. M.; Dankers, J. N. J. A.; Dahl, K.; Gätje, C.; Marencic, H.; Potel, P. Wadden Sea Quality Status Report 1999. Wadden Sea Ecosystem No. 9, Common Wadden Sea Secretariat, Trilateral Monitoring and Assessment Group, Quality Status Report Group, Wilhelmshaven, Germany, 1999; pp 125-129.

(19) Harding, K. C.; Härkönen, T.; Caswell, H. The 2002 European seal plague: epidemiology and population consequences. Ecol. Lett. 2002, 5, 727-732.

(20) Jensen, T.; van de Bildt, M.; Dietz, H. H.; Andersen, T. H.; Hammer, A. S.; Kuiken, T.; Osterhaus, A. Another phocine distemper outbreak in Europe. Science 2002, 297, 209.

(21) Hansen, K. J.; Clemen, L. A.; Ellefson, M. E.; Johnson, H. O. Compound-specific, quantitative characterization of organic fluorochemicals in biological matrixes. Environ. Sci. Technol. 2001, 35, 766-770.

(22) Hoff, P. T.; Van de Vijver, K. I.; Van Dongen, W.; Esmans, E. L.; Blust, R.; De Coen, W. Perfluorooctane sulfonate in bib (Trisopterus luscus) and plaice (Pleuronectes platessa) from the Western Scheldt and the Belgian North Sea: distribution and biochemical effects. Environ. Toxicol. Chem. 2003, 22, 608614

(23) Das, K.; Drouguet, O.; Van de Vijver, K. I.; Jauniaux, T.; Reijnders, P. J. H.; Siebert, U.; Bouquegneau, J. M. Ecological and pathological factors related to trace metal concentrations in the harbour seal (Phoca vitulina), in preparation.

(24) Das, K.; Lepoint, G.; Leroy, Y.; Bouquegneau, J. M. Marine mammals from the Southern North Sea: insights in their feeding ecology from ${ }^{13} \mathrm{C}$ and ${ }^{15} \mathrm{~N}$ measurements. Mar. Ecol.: Prog. Ser. 2003b, 263, 287-298.

(25) Boon, J. P.; ven der Meer, J.; Allchin, C. R.; Law, R. J.; Klungsoyr, J.; Leonard, P. E. G.; Spliid, H.; Storr-Hansen, E.; Mckenzie, C. Wells, D. E. Concentrations-dependent changes of PCBs patterns in fish eating mammals: structural evidence fro induction of cytochrome p450. Arch. Environ. Contam. Toxicol. 1997, 33, 298-311.

(26) Kannan, K.; Corsolini, S.; Falandysz, J.; Oehme, G.; Focardi, S. Giesy, J. P. Perfluorooctanesulfonate and related fluorinated hydrocarbons in marine mammals, fishes, and birds from coasts of the Baltic and the Mediterranean Seas. Environ. Sci. Technol. 2002, 36, 3210-3216.

(27) Kannan, K.; Koistinen, J.; Beckmen, K.; Evans, T.; Gorzelany, J. F.; Hansen, K. J.; Jones, P. D.; Helle, E.; Nyman, M.; Giesy, J. P. Accumulation of perfluorooctane sulfonate in marine mammals. Environ. Sci. Technol. 2001, 35, 1593-1598.

(28) Martin, J. W.; Mabury, S. A.; Solomon, K. R.; Muir, D. C. G. Bioconcentration and tissue distribution of perfluorinated acids in rainbow trout (Oncorynchus mykiss). Environ. Toxicol. Chem. 2003, 22, 196-204.

(29) Hoff, P. T.; Scheirs, J.; Van de Vijver, K.; Van Dongen, W.; Esmans, E. L.; Blust, R.; De Coen, W. M. Biochemical effect evaluation 
of perfluorooctane sulfonate acid-polluted wood mice (Apodemus sylvaticus). Environ. Health Perspect. 2004, 112, 681686.

(30) Thilly, W. G. Have environmental mutagens caused oncomutations in people? Nat. Genet. 2003, 34, 255-259.

(31) U.S. Environmental Protection Agency. Perfluorooctyl sulfonates; proposed significant new use rule. Fed. Regist. 2000, $65,62319-62333$.

(32) Taniyasu, S.; Kannan, K.; Horii, Y.; Hanari, N.; Yamashita, N. A survey of perfluorooctane sulfonate and related perfluorinated organic compounds in water, fish, birds and humans from Japan. Environ. Sci. Technol. 2003, 37, 2634-2639.

(33) Gurunge, K. S.; Taniyasu, S.; Miyazaki, S.; Yamanaka, N.; Yamashita, N. Age dependent accumulation of perfluorinated chemicals in beef cattle. Fluorinated POPs 2004, 66, 4029-4034.

(34) Yamashita, N.; Kannan, K.; Taniyasu, S.; Horii, Y.; Hanari, N.; Okazawa, T.; Petrick, G. Environmental contamination by perfluorinated carboxylates and sulfonates following the use of fire-fighting foam in Tomakomai, Japan. Fluorinated POPs 2004, $66,4063-4068$.

(35) Lau, C.; Butenhoff, J. L.; Rogers, J. M. The developmental toxicity of perfluoroalkyl acids and their derivates. Toxicol. Appl. Pharm. 2004, 198, 231-241.

(36) Yang, Q.; Xie, Y.; Depierre, J. W. Effects of peroxisome proliferators on the thymus and spleen of mice. Clin. Exp. Immunol. 2000, 122, 219-226.

(37) Kaijwara, N.; Watanabe, M.; Tanabe, S.; Nakamatsu, K.; Amano M.; Miyazaki, N. Specific accumulation and temporal trends of organochlorine contaminants in Dall's porpoises (Phocoenoides dalli) from Japanese coastal waters. Mar. Pollut. Bull. 2002, 44, 1089-1099.

Received for review May 17, 2005. Revised manuscript received July 14, 2005. Accepted July 14, 2005.

ES050942+ 